\title{
Molybdenum isotope fractionation in Tibet magmatism
}

\author{
Y.-H. LIANG ${ }^{1 *}$, D.-C. LEE ${ }^{1}$, S.-L. CHUNG ${ }^{1}$
}

${ }^{1}$ Institute of Earth Sciences, Academia Sinica, 128, Sec. 2,

Academia Road, Nangang, Taipei 11529, Taiwan

(*correspondence: yuhsuanl@earth.sinica.edu.tw)

As one of the redox-sensitive element, Mo isotope system has been largely applied on the researches of ocean-chemistry and paleo-redox condision in the past couple decades. However, the potential appilcation of its fractionation under high-temperture processes is still developing. Molybdenum has long been considered as the most strongly depleted of the moderately siderophile, refractory elements in the Bulk Silicate Earth (BSE), showing an apparent well-defined $\sim 70$ fold reduction relative to refractory lithophile elements as a result of core formation [1]. Previous research about worldwide mantle derived mafic and ultramafic rocks indicated Mo isotope may fractionate during partial melting [2]. Moreover, the isotopic fractionation within Palaeozoic granitic rocks suggested the Mo isotope composition in granites may be affected by igneous processes, source mixing, regional geology, or hydrothermal activity [3]. These earlier studies suggested that the Mo isotope composition may vary between geological reservoirs.

For the extensive investigation in Mo isotope signature of different phases and reservoirs, we analyze few wellcharacterised S-type and A-type like Tibetan granitoids dated between Cretaceous and Paleocene. The Mo isotope composition of these granitoids are lighter than estimated BSE value [2], and this is consistent with the result of partial melting on suggested isotopically lighter lower crust $[3,4]$ or sbubcontinental lithospheric mantle. However, comparing to Cretaceous granitoids, Paleocene granitoids were $\sim 0.4 \%$ o lighter on the mean $\delta^{98 / 95}$ Mo value. This fractionation might be resulted from the changing of magma source or tectonic setting during India-Asia convergence. While the aqueous fluid derived from the subducting slab has been suggested as a source of heavy Mo component [4], the Mo isotope variation between granitoids may indicate the slab rollback/breakoff event took place under Tibetan Plateau and the underlying detail needs further investigation.

[1] Palme and O'Neill (2014) Treatise on Geochemistry ( $2^{\text {nd }}$ edition) 3 1-39.

[2] Liang et al. (2017) GCA 199 91-111.

[3] Yang et al. (2017) GCA 205 168-186.

[4] Freymuth et al. (2015) EPSL 432 176-186. 